Article

\title{
Development of an Innovation Model Based on a Service-Oriented Product Service System (PSS)
}

\section{Seungkyum Kim ${ }^{1}$, Changho Son ${ }^{2}$, Byungun Yoon ${ }^{3}$ and Yongtae Park ${ }^{1, *}$}

1 Department of Industrial Engineering, Seoul National University, 1 Gwanak-ro, Gwanak-gu, Seoul 151-742, Korea; E-Mail: hdglace8@snu.ac.kr

2 Department of Weapon System Engineering, Korea Army Academy at Yeong-Cheon, 135-1 Changhari, Young-Cheon, Gyeongbuk 770-849, Korea; E-Mail: c13981@snu.ac.kr

3 Department of Industrial \& Systems Engineering, Dongguk University, Seoul 04620, Korea;

E-Mail: postman3@dongguk.edu

* Author to whom correspondence should be addressed; E-Mail: parkyt1@snu.ac.kr; Tel./Fax: +82-2-878-3511.

Academic Editor: Adam Jabłoński

Received: 1 August 2015 / Accepted: 20 October 2015 / Published: 28 October 2015

\begin{abstract}
Recently, there have been many attempts to cope with increasingly-diversified and ever-changing customer needs by combining products and services that are critical components of innovation models. Although not only manufacturers, but also service providers, try to integrate products and services, most of the previous studies on Product Service System (PSS) development deal with how to effectively integrate services into products from the product-centric point of view. Services provided by manufacturers' PSSes, such as delivery services, training services, disposal services, and so on, offer customers ancillary value, whereas products of service providers' PSSes enrich core value by enhancing the functionality and quality of the service. Thus, designing an effective PSS development process from the service-centric point of view is an important research topic. Accordingly, the purpose of this paper is to propose a service-oriented PSS development process, which consists of four stages: (1) strategic planning; (2) idea generation and selection; (3) service design; and (4) product development. In the proposed approach, the PSS development project is initiated and led by a service provider from a service-centric point of view. From the perspective of methodology, customer needs are converted into product functions according to Quality Function Deployment (QFD), while Analytic Hierarchy Process (AHP) is employed to prioritize the functions. Additionally, this paper illustrates a service-oriented PSS development that demonstrates the application of the
\end{abstract}


proposed process. The proposed process and illustration are expected to serve as a foundation for research on service-oriented PSS development and as a useful guideline for service providers who are considering the development of a service-oriented PSS.

Keywords: Product Service System (PSS); service-oriented PSS development process; English education; Analytic Hierarchy Process (AHP); Quality Function Deployment (QFD)

\section{Introduction}

Recently, customer needs have become increasingly diversified and ever-changing. Under this circumstance, because it is very difficult to fulfill sophisticated customer needs by product innovation alone, many attempts to overcome this problem have involved combining products and services. In practice, companies, such as General Electric, Xerox, Canon, and Parkersell, have shown a considerable increase in sales and profits from services since the mid-1990s [1]. Although such companies had originally made profits by only selling products, they have maintained growth by integrating services into their products. These attempts can be regarded as Product Service Systems (PSS), which are firstly defined as a set of products and services that fulfills customer needs and has lower environmental impact [2]. Most of the early studies on PSS focused on the environmental aspect. However, the scope and concept of PSS have been expanded, as various studies on PSS have been actively conducted. Nowadays, PSS is regarded as an integrated system of products and services to provide customers with functions and value that they need [3]. Thus, it is one of the critical components of innovation models that can create value on existing and new businesses.

Most of the previous studies on PSS are based on the viewpoint of manufacturers [4-11]. Particularly, studies on PSS development deal with how to effectively integrate services into products from the product-centric point of view, and they focus on a specific phase, not the whole development process. Low et al. [4] suggested an idea generation method using theory of solving inventive problem (TRIZ) methodology, while Uchihira et al. [8] proposed a method that identifies PSS opportunities along with product usage. Aurich et al. [6] and Yang et al. [11] utilized product life-cycle data for idea generation and design of PSSes. In summary, there is a lack of research on PSS development covering the whole development process, and it is rare to find PSS research conducted from the service-centric point of view. However, service providers are also making attempts to integrate products into their services for effective service deliveries and differentiated customer value. Amazon's Kindle is an example of this case. PSSes developed by manufacturers and service providers have different characteristics in terms of customer value. Services of manufacturers' PSSes, such as delivery services, training services, disposal services, and so on, offer customers ancillary value instead of core value that customers recognize when consuming the product, whereas products of service providers' PSSes ensure that core value is enriched by enhancing functionality and quality of the service. In the case of Kindle, e-book contents are instantly delivered with lower cost, easier access, and easier payment; therefore, Kindle enriches the core value that Amazon has offered customers as an online bookstore. Thus, a different approach for developing a service-centric PSS is required. Therefore, designing an effective PSS development process from the service-centric point of view is an important research topic. 
Accordingly, this paper proposes a service-oriented PSS development process in which the PSS development project is initiated and led by a service provider from a service-centric viewpoint to generate a new innovation model. In contrast to a single product or service development, PSS development is carried out by multiple actors, including manufacturers and service providers; hence, the role of each actor should be defined clearly. In the proposed process, which consists of four stages, the actor and its role are specified for each stage. Additionally, this paper introduces a real PSS development case from the education industry sector, which demonstrates the application of the proposed process and discusses the practical issues that can occur during the PSS development project. The fact that the proposed process was applied to real business practices has practical significance and, furthermore, this research could serve as a useful guideline for service providers to develop a service-oriented PSS.

The remainder of this paper is organized as follows. In the next section, the previous studies on PSS development are reviewed, which build a foundation for the proposed approach. In Section 3, a service-oriented PSS development process is proposed including the concept, framework, and detailed processes. Section 4 introduces the case of service-oriented PSS development in detail. Finally, this research ends with conclusions that include contributions, limitations and directions for future research.

\section{Literature Review}

\subsection{Definition of PSS}

Recently, PSS has received much attention from both industry and academia. Accordingly, active research regarding PSS is underway. Goedkoop et al. [2] initially suggested the PSS concept, which is defined as "a system of products, services, networks of players, and supporting infrastructure that continuously strives to be competitive, satisfy customer needs and have a lower environmental impact than traditional innovation models" [2]. On the other hand, Wong [12] defined PSS as follows; "Product Service-Systems (PSS) may be defined as a solution offered for sale that involves both a product and a service element, to deliver the required functionality", which was not limited to the environmental impact. Although many researchers have since proposed different definitions of PSS, it has generally been considered as "product(s) and service(s) combined in a system to enable new innovation models aiming to fulfill customer needs" [2,3,13,14].

\subsection{Characteristics of PSS}

The main characteristics of PSS, in comparison with pure products or services, are threefold. First, firms can improve the level of interaction with their customers through PSS. In terms of customer relationships, the products, and services offered through PSS play a complementary role in satisfying the customers' requirements. For instance, if a company that sells washing machines also provides laundry service to its customers, the interaction with customers will be increased because of the characteristics of this add-on service. Second, there are a variety of types of payment and ownership of PSS [15]. This is because PSS is an integrated model of ownable and tangible products and non-owned and intangible services. Accordingly, most PSS providers have ownership of their PSS and sell the usage rights or results. Tukker [15] suggested three main categories of PSS, including 
product-oriented services, use-oriented services, and result-oriented services. In case of use-oriented services and result-oriented services, the payment reference is not for the product, but a payment per unit time or unit use, and so on. The product stays in ownership with the provider in the above cases, whereas products are mainly sold and some extra services are added in product-oriented services. Here, there is no pre-determined product involved for result-oriented services.

Lastly, stakeholders creating PSS value are very diverse [16,17], including PSS providers and customers. A representative example where integrated products and services are provided through collaboration among several firms is Apple's AppStore.

\subsection{Types of PSS}

The most widely accepted of the proposed PSS types is the work by Tukker [15]. The three main categories are as follows: product-oriented PSS, use-oriented PSS, and result-oriented PSS. First, the product-oriented PSS is the most similar to the concept of the traditional product, since the value is achieved by selling the product. However, this is accompanied by additional services such as after-sales services to guarantee the functionality of the product. Second, use-oriented PSS basically sells the "use" of a product, not the product itself. What is delivered to the customer is a function that the customer wants, for example, leasing or sharing services. Finally, result-oriented PSS sells a result or capability instead of a product. The customer pays only for the provision of agreed results. Selling laundered clothes instead of a washing machine is a good example of result-oriented PSS [3,15].

\subsection{Research on PSS Development Process}

Most studies of the PSS development process have been based on the development process of products or services and consist of three main phases: analysis, idea generation, and selection, and implementation [17]. The first phase, analysis, includes environmental analysis, SWOT analysis, and so on, which has been treated as a small part of PSS development research. Nevertheless, some methodologies have been developed and employed in the analysis phase. The "Innovation Scan" was developed for analyzing and forecasting the relationship between customer needs and product functions [18], while the product-service integrated roadmap was proposed for the strategic planning of product-service integrated offerings [19]. The next phase, idea generation and selection, has been the most actively studied. Lee and Kim [20] classified PSS by function and developed PSS ideas using a combination of products and services. Low et al. [4], Chen and Huang [21], and Chen and Li [22] utilized TRIZ for idea generation. The TRIZ method stands for "Teoriya Resheniya Izobretatelskikh Zadatch" in Russian which means theory of inventive problem solving [23,24]. This method solves technical problems and offers innovative product structures by employing a knowledge base built from the analyses of approximately 2.5 million patents, primarily on mechanical design [25]. TRIZ consists of three basic tools: (1) 40 principles to resolve conflicts effectively; (2) a knowledge database system that consists of physical, chemical, and geometrical effects and rules for problem solving; and (3) modeling a technological problem.

Uhlmann and Stelzer [26] suggested seven dimensions to determine PSS ideas through a case study. The seven dimensions are composed of customer skills, customer will to build up skills, property 
rights, human resources, outsourcing of product, existing network of suppliers, and process monitoring to determine PSS ideas through a case study.

Meiner and Kroll [27] proposed an approach to creating a new PSS model based on service processes. In addition, many tools, such as extended service blueprint [10], system map, interaction storyboard, stakeholder motivation matrix [28], modified IDEF0 [29], and many others to design PSSes using generated and selected new ideas have been developed. Finally, in the implementation phase, Schuh and Gudergan [30] suggested a framework using QFD (Quality Function Deployment) and Yang et al. [11] provided a methodology for the realization of PSSes through the utilization of product life-cycle data. The QFD has been widely used since Akao suggested it in 1990. The tool that has been used most frequently in QFD is a matrix called the House Of Quality (HOQ), which is utilized for the aim of converting market information into product strategies for business [31].

As we have explained, most previous research on PSS development has focused on a specific phase, not the whole development process. In particular, these studies have been mainly conducted from the product-centric point of view. In other words, previous studies of PSS development dealt with products and relevant supporting services, but the converse was not the case. While the term, "service-oriented product" was utilized in some studies [32,33], it represented use-oriented PSS rather than service-supporting products. Therefore, research on the entire development process for service-oriented PSS is still the domain of a few pioneers.

\section{Service-Oriented PSS Development}

\subsection{Concept}

This research proposes the service-oriented PSS development process for developing a new innovation model. The term, "service-oriented PSS" stands for a PSS in which a product is integrated into a service as a supporting tool to make the existing service more competitive. The distinctive characteristics of the service-oriented PSS are twofold. First, customer needs for the existing service are the starting point of service-oriented PSS development, whereas product-centric PSS development begins with the needs for the product itself or the context of product usage. After customer needs for the service are investigated, the product functions to fulfill these needs are derived from the investigation result. Subsequently, new services are developed by combining the existing service with the new product. Where a single service cannot meet customer needs without a product, it can be complemented by the integration of the service and product. That is to say, functions required for the product are derived from customer needs for the service, and the product makes the service more competitive. The integration of the service and product constitutes the service-oriented PSS, which can provide greater competitiveness and value than a stand-alone service.

Second, in service-oriented PSS development, the role of the product manufacturer should receive greater emphasis than that of the service provider in product-centric PSS development. Most previous studies on PSS development considered services as the means to offer customers ancillary value in order to raise lock-in effects and sales from the manufacturers' viewpoint, and manufacturers introduce and operate their own services in many cases [7]. On the other hand, it is hard for service providers to develop and produce products. In a relative sense, products are dependent on technologies, equipment, 
and facilities, whereas services are dependent on humans. Thus, service providers should establish strong partnerships with manufacturers to develop service-oriented PSSes and closely collaborate with partners on product and service developments. In these regards, service-oriented PSS development differs from product-centric PSS development.

\subsection{Framework}

The service-oriented PSS development process proposed in this research is derived from the product development process of Cooper et al. [34,35], the service development process of Brügemann [36], and several cases of PSS development projects summarized by Tukker and Tischner [17]. The product development process of Cooper et al. [34,35] is represented by the stage-gate process which comprises a five-stage (scoping, build business case, development, testing and validation, and launch), five gate (idea screen, second screen, go to development, go to testing, and go to launch) process incorporating a discovery stage and a post-launch review, whereas the service development process of Brügemann [36] is composed of eight stages: "situation analysis", "objectives", "strategy", "idea finding", "generation of requirements", "development", "implementation", and "delivery of service". Tukker and Tischner [17] investigated PSS development methods used in PSS development projects and grouped them into three phases, "analysis", "idea generation and selection", and "implementation". Based on these references, we made the service-oriented PSS development process by grouping similar stages and excluding stages related to marketing, distribution, and use in order to focus on development. The result consists of four stages, "strategic planning", "idea generation and selection", "service design", and "product development". Between every stage, an intermediate evaluation and back-loop scheme using the results of intermediate evaluation is applied like Cooper et al.'s five gates. Contrary to the previous sequential processes, the proposed process is a hybrid of sequential and parallel processes, because PSS development includes product development as well as service development. The planning and idea generation for PSS development are carried out sequentially and service design proceeds in parallel with product development.

As shown in Figure 1, the service-oriented PSS development process has two layers, a service provider layer and product partner (manufacturer) layer, which show the participants for each stage. Service-oriented PSS development is initiated by the service provider, hence the first stage, "strategic planning" is carried out by the service provider alone. The next stage, "idea generation and selection" is performed by the service provider and the product partner selected in the previous stage. Together they generate detailed ideas for planned PSS development. Subsequently, the third and fourth stages, "service design" and "product development", are conducted concurrently by the service provider and the product partner, respectively. At this time, the key aspect to successful PSS development is to achieve consensus on the service and product through effective communication and interaction between the two actors. To this end, the results of service design should be delivered to the product partner in order to verify the technical feasibility of the required service functions, and the pilot product should also be delivered to the service provider in order to judge the suitability of the design and functions. These collaborations are expressed as arrows between "service design" and "product development" in Figure 1. Here, a service-oriented PSS can be developed from the open innovation concept of Chesbrough [37]. From a service-centered point of view, product partners can be 
considered as external; i.e., the use of purposive inflows and outflows of knowledge is to accelerate internal innovation and expand the markets for external use of innovation. Actors and key features for each stage of the service-oriented PSS development process are summarized in Table 1.

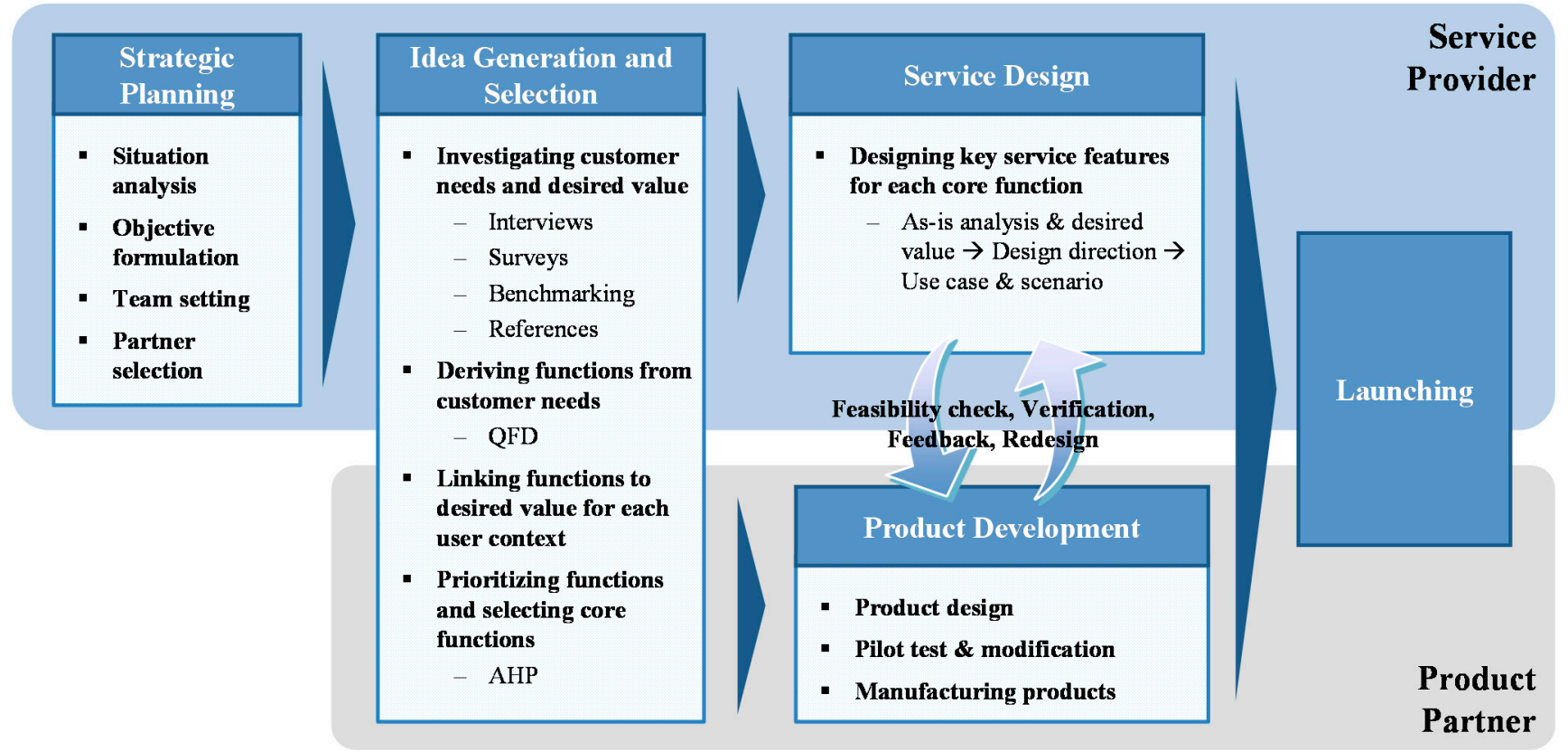

Figure 1. Service-oriented PSS development process.

Table 1. Actors and key features for each stage of the service-oriented PSS development process.

\begin{tabular}{|c|c|c|c|}
\hline \multicolumn{2}{|c|}{ Stage } & Actor & Key Feature \\
\hline \multicolumn{2}{|c|}{ Strategic Planning } & Service Provider & $\begin{array}{l}\text { The service-oriented PSS development } \\
\text { is initiated by the service provider, } \\
\text { and a product partner is selected. }\end{array}$ \\
\hline \multicolumn{2}{|c|}{ Idea Generation and Selection } & $\begin{array}{c}\text { Service Provider \& } \\
\text { Product Partner }\end{array}$ & $\begin{array}{l}\text { During this stage, there is a preliminary check } \\
\text { of the feasibility of the ideas and consensus on } \\
\text { the detailed PSS concept is achieved through } \\
\text { collaboration between the two actors. }\end{array}$ \\
\hline \multirow[b]{2}{*}{$\begin{array}{c}\text { PSS } \\
\text { Development }\end{array}$} & Service Design & Service Provider & \multirow{2}{*}{$\begin{array}{l}\text { Detailed service features and product } \\
\text { functions are verified and redesigned based on } \\
\text { feedback. Finally, the final service-oriented } \\
\text { PSS is developed. }\end{array}$} \\
\hline & $\begin{array}{c}\text { Product } \\
\text { Development }\end{array}$ & Product Partner & \\
\hline \multicolumn{2}{|c|}{ Launching } & $\begin{array}{l}\text { Service Provider \& } \\
\text { Product Partner }\end{array}$ & $\begin{array}{c}\text { The service-oriented PSS is launched } \\
\text { in the market. }\end{array}$ \\
\hline
\end{tabular}

\subsection{Detailed Process}

\subsubsection{Strategic Planning}

A service-oriented PSS development project is initiated by the service provider and the first stage is strategic planning. First, the service provider determines what to develop. In the case that services, alone, are provided, the service provider builds a general concept of PSS development that combines 
the existing services and product in order to increase competitiveness and customer satisfaction as well as add new value for customers. Thereafter, the service provider conducts situation analyses, including market analysis, competence analysis, competitor analysis, and so on. Subsequently, the concrete objectives of the PSS development project and the team that will lead it are formulated. Lastly, the product partner that will cover the product development is selected. The selection of a product partner to develop the service-oriented PSS can be accomplished through a variety of methods. Among them, an emergent theory of partner selection through collaboration, similar to that produced by Emden et al. [38], is utilized. The model is composed of three broad phases: (1) technological alignment; (2) strategic alignment; and (3) relational alignment. Technological capability, resource complementarity, and overlapping knowledge bases are considered in the first phase. Then, motivation and goal correspondence are checked in the second phase. Finally, compatible cultures, propensity to change, and long-term orientation are screened in the third phase.

\subsubsection{Idea Generation and Selection}

The second stage is idea generation and selection, which are conducted by the service provider and the product partner selected in the previous stage. In this stage, it is essential to investigate customer needs for the existing service and derive product functions from these needs. To this end, expected user groups are firstly selected, and each group's needs for the existing service are investigated thoroughly. At this point, not only customer needs but also their desired requirements i.e., what they ultimately want from the service, should be identified. Interviews and surveys are the most useful and representative methods for this purpose. Particularly, in-depth interviews with customers and related experts are an effective means to figure out the ideal service scenarios and product functions required when the service is combined with the product. In addition, reviews in relevant professional publications and reports, and benchmarking of existing relevant services and products can provide the implications of success and failure factors that help derive product functions.

The next step is to derive product functions based on prior investigations of customer needs. At this point, customer needs are converted into product functions in a similar manner to QFD, which transforms customer needs into engineering/process requirements. Subsequently, additional functions can be added from the benchmarking results. Eventually, the customer needs generated from the service are analyzed and converted into product functions.

The following step is to match up functions with desired requirements using QFD. The desired requirements can be varied according to the purpose and situation of each user group. Thus, the functions that will be provided should differ in accordance with user groups. To deal with this problem, the actors in this stage should analyze the user context and derive desired requirements according to each user group's context based on the results of the investigation conducted previously. Subsequently, actors match every function with certain desired requirements and user groups. Consequently, the results can show a user group and its desired requirements provided by a specific function, functions needed by a specific user group, and functions that fulfill certain desired requirements. An exemplified outcome of this task is illustrated in Figure 2.

Lastly, functions are prioritized by the Analytic Hierarchy Process (AHP) method and core functions are selected as the final outcome of this stage. The AHP is a decision-aiding method 
developed by Saaty [39-41]. It is one of the most widely used multi-criteria decision-making tools and is an Eigenvalue approach to pair-wise comparisons. It also provides a methodology to calibrate the numeric scale for the measurement of both quantitative and qualitative performances [42]. The number of core functions can vary according to constraints such as project schedule and financial budget, and the remaining functions can be developed and added to the next version of the PSS. Through the previous steps such as investigating customer needs and desired requirements, deriving functions, and linking functions with desired requirements, participants in this stage can be regarded as experts who have sufficient knowledge about the desired requirements and the necessary functions. Thus, they can evaluate the relative importance between two functions based on their experiences when using the AHP method.

\begin{tabular}{|c|c|c|c|c|c|c|c|c|c|c|}
\hline \multicolumn{11}{|c|}{ User group 1} \\
\hline User context & \multicolumn{3}{|c|}{ Context 1} & \multicolumn{3}{|c|}{ Context 2} & \multicolumn{3}{|c|}{ Context 3} & $\cdots$ \\
\hline Functions & DR 1-1 & DR 1-2 & $\cdots$ & DR 2-1 & DR 2-2 & $\cdots$ & DR 3-1 & DR 3-2 & $\cdots$ & $\cdots$ \\
\hline Function 1 & 0 & 0 & & & 0 & & & & & \\
\hline Function 2 & & & & 0 & & & 0 & & & \\
\hline Function 3 & & & & & 0 & & $\mathrm{O}$ & 0 & & \\
\hline Function 4 & 0 & & & 0 & & & & & & \\
\hline$\vdots$ & & & & & & & & & & \\
\hline
\end{tabular}

Figure 2. An example of a matrix for linking functions to desired requirements for each user context.

\subsubsection{Service Design}

The service design stage and the product development stage proceed in parallel under the respective guidance of the service provider and product partner after the second stage, idea generation and selection. In the service design stage, the service provider designs services in detail, which can be realized with the product functions derived in the previous stage.

Service dominant logic is comprised of five steps as follows: (1) as-is analysis; (2) setting service design direction; (3) creating service use-cases; (4) making service scenarios; and (5) checking feasibility. First, the service provider conducts the "as-is analysis", which analyzes the current situation of services offered without a product. The deficiencies in current services that are contrary to the ideal services and desired requirements are derived from "as-is analysis". Thereafter, the service provider establishes the direction of the service design for overcoming the gap between the current services and the ideal ones via integration with product functions. Subsequently, the service provider develops use-cases based on the design direction, which includes elements such as actors (users, service providers, and so on), product, and infrastructure (systems, networks, and so on.) as well as the relationships between elements such as information input/output and physical materials. After all the use cases have been developed, service scenarios for each user group can be created by aggregating them. During these tasks, modeling methods such as IDEF0 which is a compound acronym Icam DEFinition for Function Modeling, where "ICAM" is an acronym for Integrated Computer Aided Manufacturing and service blueprint [29] can be exploited. After the use cases and service scenarios 
have been developed, they are delivered to the product partner to verify the technical feasibility. Then, the service provider receives feedback on the technical feasibility of the service, and redesigns services based on this. Furthermore, the service provider should give feedback on the pilot product to the product partner.

\subsubsection{Product Development}

In this stage, the product partner develops the product. The product partner develops the basic design, architecture, and product specifications, and realizes the functions derived from the idea generation and selection. Once the pilot product is created, the product partner should deliver it to the service provider and modify its design, functions, and so on, according to the feedback from the service provider. In addition, once the product partner receives the use cases and service scenarios from the service provider, the product partner checks the feasibility to determine whether it is possible to realize the product functions required by the service or not. If there is a function that is impossible to realize, the product partner sends feedback so that the relevant service can be redesigned. Otherwise, the product partner modifies the functions, architecture, or specifications of the product according to the use cases and service scenarios. Effective and efficient interaction between the service provider and product partner is critical to develop a successful PSS. Thus, various iterations of feasibility checks, verifications, feedback and redesigns are inevitable while jointly developing the service and product. Once the final consensus on the service and product is achieved through these processes, the product partner manufactures the products. Finally, service-oriented PSS development is finished and launched. There are many factors to take into account when launching a service-oriented PSS. The launching stage needs to address some basic issues such as launch goal and strategy, major player and stakeholders, target customers, current market environment, and so on [43]. It is critical to carefully design a launch plan and prepare internally before a public launch. This internal preparation will address issues such as testing and validation, pricing, documentation, warranty, demos, sales tools, training for sale/channels/service/support, and so on.

\section{Illustration: T Smart Learning}

\subsection{Introduction to the Case Companies and the PSS Development Project}

The illustration in this paper is derived from a PSS development project undertaken by $\mathrm{S}$ Telecom in collaboration with $\mathrm{C}$ Learning. $\mathrm{S}$ Telecom is a mobile service provider in Korea, with $50.6 \%$ market share as of 2010. Since its launch on 29 March 1984 S Telecom has evolved from a first-generation analog cellular system, to a second-generation CDMA provider, and then to the world's first third-generation synchronized IMT-2000 cellular system. S Telecom also became the world's first company to commercialize HSDPA in May 2006. S Telecom provides not only mobile telecommunication services but also convergence services including media, social networking, content delivery, location-based service, platform, commerce, and a host of other options. Recently, S Telecom has been actively seeking new business opportunities to cope with B2C market saturation by developing B2B innovation models in various industry sectors, including the education industry. 
C Learning is a language institute located in Korea and Canada. C Learning was founded in 1998 and offers ESL (English as a Second Language) learning services by combining self-developed programs and native English-speaking instructors. C Learning provides more than 60,000 students with unique programs based on critical thinking and cognitive language development. This is made possible by more than 1300 instructors, 390 corporate employees, and its ESL R-and-D center. Recently, the company has reached saturation in terms of the number of students it can teach due to physical space constraints. Thus, an innovative method for continuous growth is required. Additionally, the Korean Education Ministry unveiled a plan to introduce a new English aptitude test-NEAT (National English Ability Test) - that focuses on tests of speaking and writing ability, and will replace the English section of the standardized college entrance examination. Therefore, new coursework and classes to prepare for the NEAT will have to be created.

Under this background, S Telecom and C Learning signed a memorandum of understanding on developing an English learning system that uses wireless communications networks to allow students to study anywhere and anytime, keep parents up to date with students' progress, and to increase communication between the teacher and students within the classroom. The characteristics of this system as a PSS are as follows. It consists of actors (students, parents, and instructors), contents, learning-support devices, and network infrastructures. From its inception, the project considered English learning services and learning-support devices (products) simultaneously in order to create a successful PSS that can raise the effectiveness and efficiency of learning. Accordingly, many stakeholders' needs were investigated and incorporated during the development process. Furthermore, this system will only be meaningful if customer needs are fulfilled by the services or functions offered via the product. Thus, product possession itself has no meaning. In particular, product functions were developed in order to fulfill customer needs and desired requirements that were derived and analyzed from existing English learning services. These characteristics made this English learning system a service-oriented PSS.

\subsection{Strategic Planning}

To begin, S Telecom and C Learning analyzed the global trend and potential of the English education market, the state of affairs of the major IT players (Apple, Intel, and so on) in the education sector, and local cases of device-based learning services by mobile service providers. These analyses produced the following results: (1) English education is experiencing high growth in the global market and Asia is the most promising region; (2) the focus of English education is moving toward improving fundamental listening, speaking, reading, and writing abilities, instead of grammar and reading comprehension; and (3) key success factors for a device-based learning system involve not only fine contents but also specialized functions increase the effectiveness of education. Consequently, S Telecom and C Learning set up an objective to develop a PSS that combines an English learning service and a mobile device. The first target service was the NEAT coursework, which had already been made by the R-and-D center of C Learning. The target product was a tablet PC-like device, which supports wireless data communication and provides specialized functions for effectively improving listening, speaking, reading, and writing English abilities. In addition, they made a plan to gradually expand the 
target market by adding other coursework and subjects and entering global education markets such as China and Southeast Asian countries.

Next, S Telecom and C Learning set up an exclusive TFT (Task Force Team) for developing the product. After establishing the team setting, the TFT searched for various device manufacturers and software developers in order to select product partners, and contacted them based on considerations of technological competency and quality, as well as cost. Finally, the hardware and software-product partners were selected and members from these product partners joined the TFT.

\subsection{Idea Generation and Selection}

For idea generation and selection, the TFT thoroughly investigated customer needs and desired requirements in English education. The TFT conducted in-depth interviews with more than 20 students and parents, and 20 experts in English education such as English teachers, directors of language institutes, and coursework developers so that users' and teachers' needs for existing English learning services and ideal methods of learning English were investigated. Additionally, the TFT reviewed eight books about the theory of English learning and 11 autobiographies by people who were successful in learning English. They also benchmarked 52 on/offline learning services and 36 learning-support devices. This broad and deep investigation enabled the TFT to achieve a full understanding of the existing English education services. It is very important to devote sufficient time and effort to this kind of task, since it serves as the foundation of the following tasks.

After extensive investigations, the TFT derived device functions based on the investigation results. The needs were converted into functions via QFD methodology, and other functions were added based on the benchmarking results. In this process, there was a preliminary check of the feasibilities of the functions, especially by TFT members who joined from product partners. For example, the "eyeball tracking" function was excluded due to technical problems and cost. Finally, 149 functions were derived. Examples of customer needs and relevant functions are summarized in Table 2.

Table 2. Examples of customer needs and relevant functions.

\begin{tabular}{|c|c|c|}
\hline User Group & Need & Function \\
\hline Student & $\begin{array}{l}\text { "Although I cannot understand what is said in class, } \\
\text { I hesitate to ask a question." } \\
\text { "I want learning to be more interesting." } \\
\text { "I want more exposure to English." }\end{array}$ & $\begin{array}{l}\text { Evaluating the current level, } \\
\text { Daily test, Learning history, Learning game, } \\
\text { Role-play, Avatar, Online community, } \\
\text { Push contents, and etc. }\end{array}$ \\
\hline Teacher & $\begin{array}{l}\text { "I want to arouse students' interest with teaching } \\
\text { materials made of multimedia contents such as } \\
\text { movies, sitcoms, news, and pop songs." } \\
\text { "In the class, it takes too much time to correct each } \\
\text { student's speaking and writing." } \\
\text { "I want to check homework and score exams } \\
\text { more efficiently." }\end{array}$ & $\begin{array}{l}\text { Coursework generator, Multimedia contents } \\
\text { library, Speaking evaluation, Writing } \\
\text { evaluation, Auto-grading, Class planner, } \\
\text { Student profile management, and etc. }\end{array}$ \\
\hline Parent & $\begin{array}{l}\text { "I wonder my child follows the coursework well." } \\
\text { "I want to know how much my child's achievement } \\
\text { level is improving." }\end{array}$ & $\begin{array}{l}\text { Informing of diagnosis results, } \\
\text { Informing of progress, } \\
\text { Informing of attitude in class, and etc. }\end{array}$ \\
\hline
\end{tabular}


The following step involves matching functions with desired requirements as well as the user context for each user group using QFD. This task was conducted through a one-day workshop attended by all members of the TFT, whereas previous tasks such as interviews, benchmarking, and function derivation were assigned to groups composed of two or three members. The TFT divided users into three groups: student, teacher and parent. For each group, the TFT analyzed user context and derived desired requirements in each context based on the investigation results (see Figures 3 and 4). Finally, 34 function sets were derived by grouping similar functions among 149 functions.

\begin{tabular}{|c|c|c|c|c|c|c|c|c|c|c|c|}
\hline \multicolumn{12}{|c|}{ Student } \\
\hline \multirow{2}{*}{$\begin{array}{l}\text { User context \& } \\
\text { Functions } \\
\mathbf{D R}^{*}\end{array}$} & \multirow{2}{*}{$\cdots$} & \multicolumn{5}{|c|}{ Speaking } & \multicolumn{4}{|c|}{ Listening } & \multirow{2}{*}{$\cdots$} \\
\hline & & $\begin{array}{l}\text { Mimicking } \\
\text { /shadowing }\end{array}$ & $\begin{array}{l}\text { Imitation/ } \\
\text { reproduction }\end{array}$ & $\begin{array}{l}\text { Present- } \\
\text { ation }\end{array}$ & Debate & $\cdots$ & $\begin{array}{l}\text { Recog- } \\
\text { nizing }\end{array}$ & $\begin{array}{c}\text { Skim- } \\
\text { ming }\end{array}$ & $\begin{array}{c}\text { Scan- } \\
\text { ning }\end{array}$ & $\cdots$ & \\
\hline Text-to-speech & & 0 & & & & & 0 & 0 & 0 & & \\
\hline Record and play & & & 0 & 0 & & & & & & & \\
\hline Partial repeat & & 0 & & & & & 0 & & & & \\
\hline Memo & & & & 0 & 0 & & & 0 & 0 & & \\
\hline$\vdots$ & & & & & & & & & & & \\
\hline
\end{tabular}

Figure 3. The partial outcome of linking functions to desired requirements for students' context.

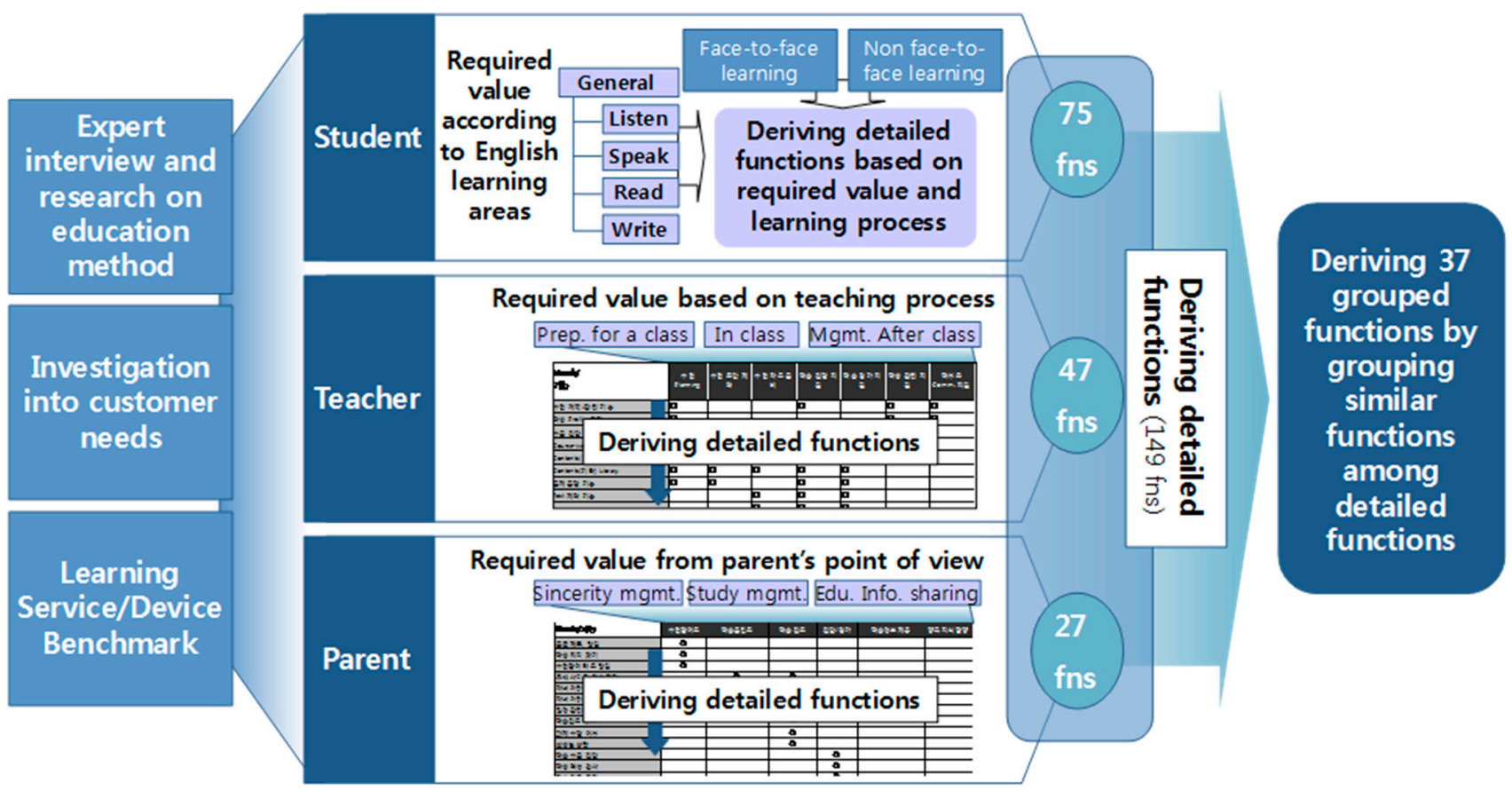

Figure 4. The partial outcome of linking functions to desired requirements for students' context.

Lastly, the TFT prioritized the function sets by the AHP method, and selected the core function sets. Since too many functions were derived, it was not reasonable to develop them all together in view of time-to-market, development cost, and quality. Thus, the TFT needed to select functions that would be developed for the first version of T Smart Learning, and the AHP method was employed for this aim. 
In addition, all members took an entire day to prioritize function sets as a group. The criteria for AHP were determined through discussion as follows: (1) effectiveness of learning; (2) personalized learning; and (3) competitiveness. After obtaining the weights for all criteria by pairwise comparisons, the TFT conducted pairwise comparisons between function sets for each criterion. Eventually, all function sets were prioritized and all consistency ratios were below 0.1 , which means that all comparisons were consistent (see Table 3). Based on the priorities, five function sets for students were selected as core function sets. Additionally, the function sets for teachers and parents were selected as core function sets in order to cover all user groups, even though these priorities were ranked below the other function sets. In the final outcome (see Appendix), the core function sets included: (1) listening-specialized function set; (2) speaking-specialized function set; (3) reading-specialized function set; (4) writing-specialized function set; (5) personal care function set; (6) teacher-support function set; and (7) parent-support function set. Other function sets will be developed and added in the next version of T Smart Learning. In this step, the AHP method was an effective means to reach a consensus on which functions would be developed first. During pairwise comparisons, the members of TFT discussed the relative importance between functions and, consequently, the consensus was built spontaneously. Thus, the AHP method served as a tool for not only prioritizing functions but also for building a consensus among TFT members.

Table 3. Priority of criteria and consistency ratio.

\begin{tabular}{ccc}
\hline Criteria & Priority & Consistency Ratio for Function Sets Evaluation \\
\hline Effectiveness of learning & 0.5438 & 0.05066 \\
Personalized learning & 0.1103 & 0.02724 \\
Competitiveness & 0.3460 & 0.03084 \\
\hline
\end{tabular}

\subsection{Service Design}

The TFT (excluding members from product partners) designed services in detail, which can be realized by utilizing the core functions derived in the previous stage. First, the TFT analyzed the deficiencies of the current English education services offered without a product, and derived the service design direction for each function set to compensate for the gap between the current situation and desired requirements investigated previously. Thereafter, the TFT created the service use-cases based on the design directions and developed service scenarios by aggregating use-cases.

The case of the speaking-specialized function set is as follows. The requirements for learning how to speak English are mimicking, imitation, reproduction, presentation, debate, self-check, and evaluation. In detail, students should listen to the native speaker's pronunciation and imitate it at the beginning. The next step is to practice various expressions that have similar meanings. Subsequently, it is necessary to improve the ability to organize the contents of what will be said. Finally, students will be able to make a presentation and participate in a debate with their own thoughts and opinions. In all these processes, self-check and evaluation can make learning more effective. However, there is little or no chance to speak English in reality. Moreover, students cannot find self-learning methods or receive instant feedback on their speaking abilities. Thus, the TFT established the design direction as follows: (1) providing various expressions recorded in a native speaker's pronunciation in order to allow 
self-practice; (2) giving instant feedback on speaking ability; and (3) offering a virtual place to communicate with colleagues via telepresence. According to these design directions, the TFT designed service use cases such as "speaking English by watching one's face via a camera in the device", "comparing one's pronunciation with a native speaker's by a record and play function", "providing a role-play service through which one can communicate with virtual characters through the device", and "providing a group discussion service via telepresence and giving instant feedback based on STT (Speech-to-Text) technology". The TFT delivered these outcomes to the product partners and received feedback from them. Subsequently, the use-cases were redesigned based on the feedback. For example, the software product partner recommended that the TFT change "giving instant feedback based on STT technology" because of the low accuracy of current STT technology. Thus, the TFT changed the concept of the feedback service from automated instant feedback to semi-automated not-instant feedback, in which manual correction by a teacher is included. The use-case of the feedback service is shown in Figure 5.

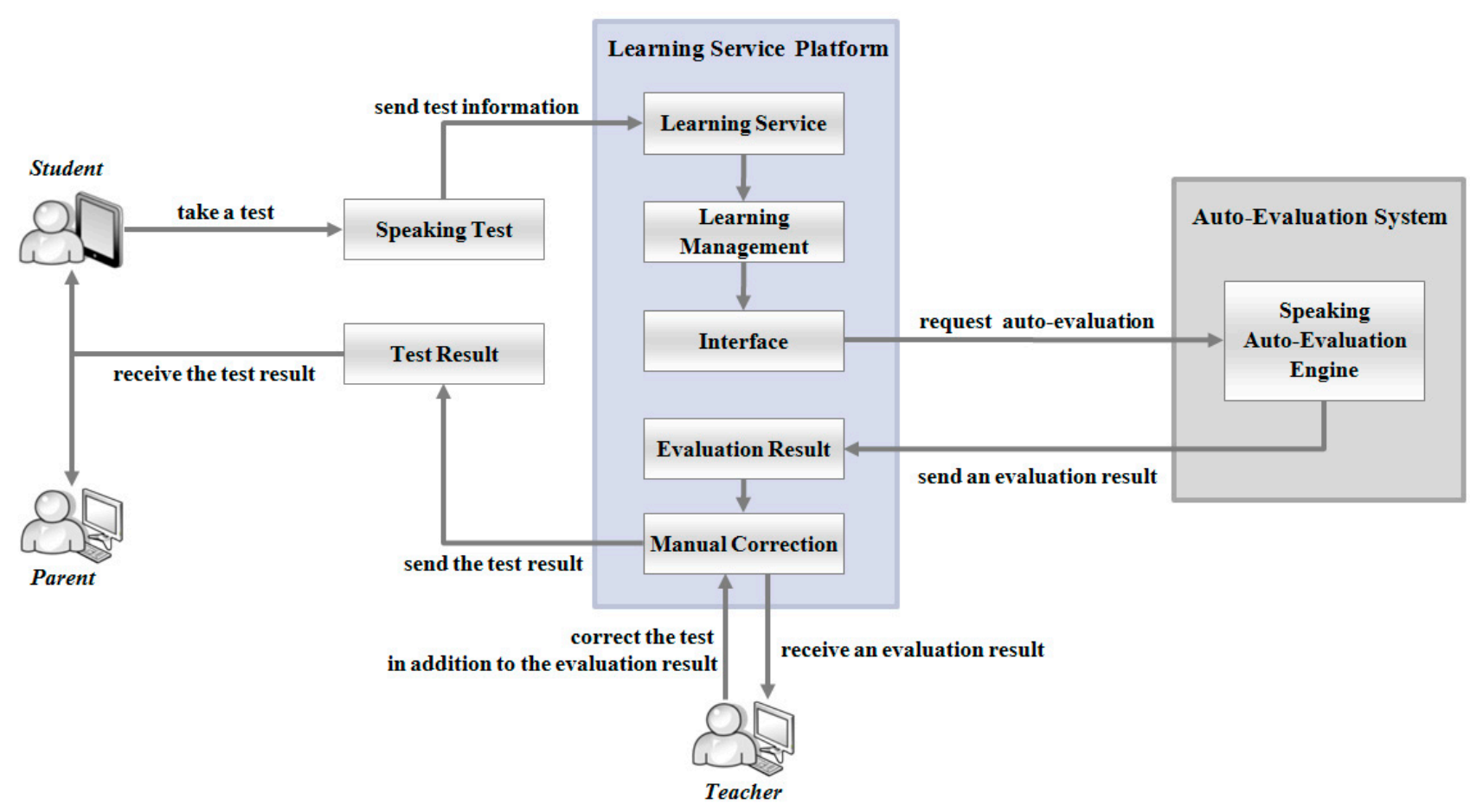

Figure 5. The use-case of the feedback service.

Finally, the TFT developed the service scenario for each user group by aggregating the service use-cases, and the partial outcome of the service scenario for the students is illustrated in Figure 6 . The service scenarios were also confirmed by the product partners. 


\begin{tabular}{|c|c|c|c|c|}
\hline & Before class & In class & After class & Learning Mgmt. \\
\hline Activity & $\begin{array}{l}\text { - Moving to the } \\
\text { classroom } \\
\text { - Preparing the class } \\
\text { - Submitting H/W } \\
\text {... }\end{array}$ & $\begin{array}{l}\text { - Speaking after listening to the } \\
\text { instructor's pronunciation } \\
\text { - Role Play, Group work, } \\
\text { presentation, etc. } \\
\text {... }\end{array}$ & $\begin{array}{l}\text { - Going home } \\
\text { - Reviewing the class } \\
\text { - Doing H/W } \\
\text {... }\end{array}$ & $\begin{array}{c}\text { - Checking the status of } \\
\text { learning (level, list of } \mathrm{H} / \mathrm{W} \text {, } \\
\text { attendance, etc.) } \\
\text {... }\end{array}$ \\
\hline $\begin{array}{l}\text { Service } \\
\text { Scenario }\end{array}$ & $\begin{array}{l}\text { - Preparing for the } \\
\text { today's contents (topic, } \\
\text { words, etc.) through } \\
\text { the device } \\
\text { - Submitting H/W } \\
\text { through the device } \\
\text {... }\end{array}$ & $\begin{array}{l}\text { - Making notes on the device and } \\
\text { saving them } \\
\text { - Conducting group work through } \\
\text { the device (collaborative writing, } \\
\text { etc.) } \\
\text { - Receiving the today's quiz and } \\
\text { submitting the result through the } \\
\text { device }\end{array}$ & $\begin{array}{l}\text { - Receiving the result of quiz and } \\
\text { feedback through the device } \\
\text { - Recoding one's voice and } \\
\text { comparing it with native's through } \\
\text { the device } \\
\text { - Learning related contents of } \\
\text { interests (news, novel, etc.) through } \\
\text { the device }\end{array}$ & $\begin{array}{l}\text { - Receiving the information of } \\
\text { current status and } \\
\text { recommendation through the } \\
\text { device (attendance rate, class } \\
\text { activity, current level and } \\
\text { goal, history of test results, } \\
\text { comments on tests and } \mathrm{H} / \mathrm{W} \text {, } \\
\text { etc.) } \\
\text {... }\end{array}$ \\
\hline
\end{tabular}

Figure 6. The partial outcome of the service scenario for the student.

\subsection{Product Development}

The respective hardware and software-product partners developed the hardware and software products that could realize the core functions derived in the idea generation and selection stage. During the development process, the product partners received service use-cases and scenarios from the TFT and incorporated them into the product development. Furthermore, the product partners communicated with the TFT continuously to receive feedback on the intermediate outcomes, and modified the products accordingly. The hardware product partner intended to develop a new device that specialized in learning, and the software product partner intended to develop a new software platform and related applications for the device based on Android open-source software.

However, it was hard to complete the hardware product development before the scheduled date. When considering the quality, cost, and release timing, the TFT and product partners decided to apply an existing tablet PC for the first version. Accordingly, the TFT and the hardware product partner consented to develop a learning-specialized device based on a long-term plan, whereas the software product partner developed the application launcher that would make an Android OS-based tablet PC operate as a new learning device. In this case, the application launcher can be regarded as another OS operating on top of the Android OS. While developing the software product, the software product partner improved the user interface and functions according to feedback from the TFT. Although the shape and specifications of the device are identical with the existing general-purpose tablet PC, the device with the launcher can provide an entirely new English-learning experience. In addition to the launcher, the software product partner developed a system comprised of the architecture, platform, and servers, which is indispensable for operating a service based on a mobile network and device (see Figure 7). Finally, S Telecom and C Learning launched a service-oriented PSS, T Smart Learning, on 18 July 2011, after a one month pilot test. The actual appearance of T Smart Learning is shown in Figure 8. The left figure is the main screen of $\mathrm{T}$ Smart Learning and the right one is the screen studying English. 


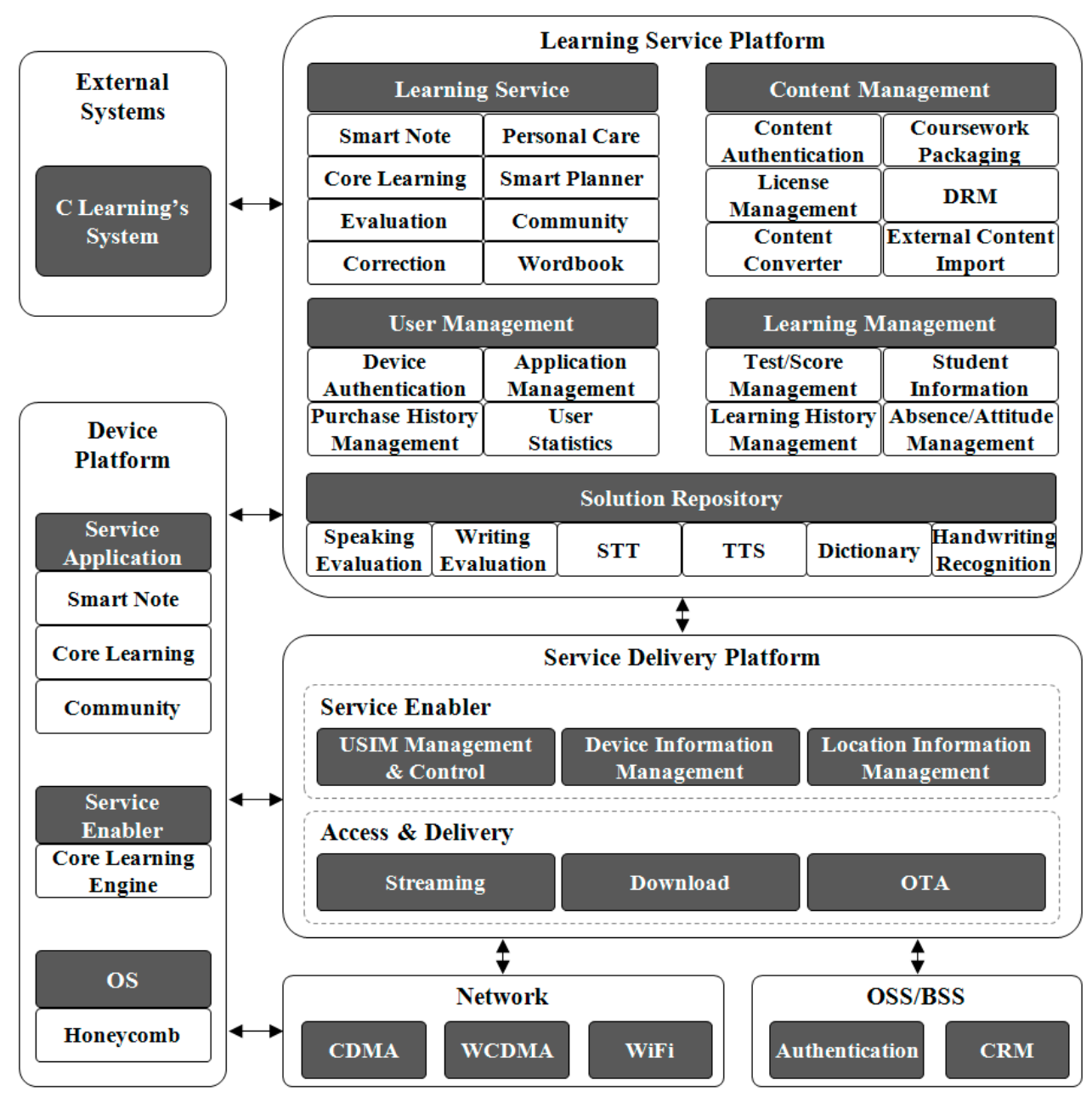

Figure 7. System architecture of T Smart Learning.
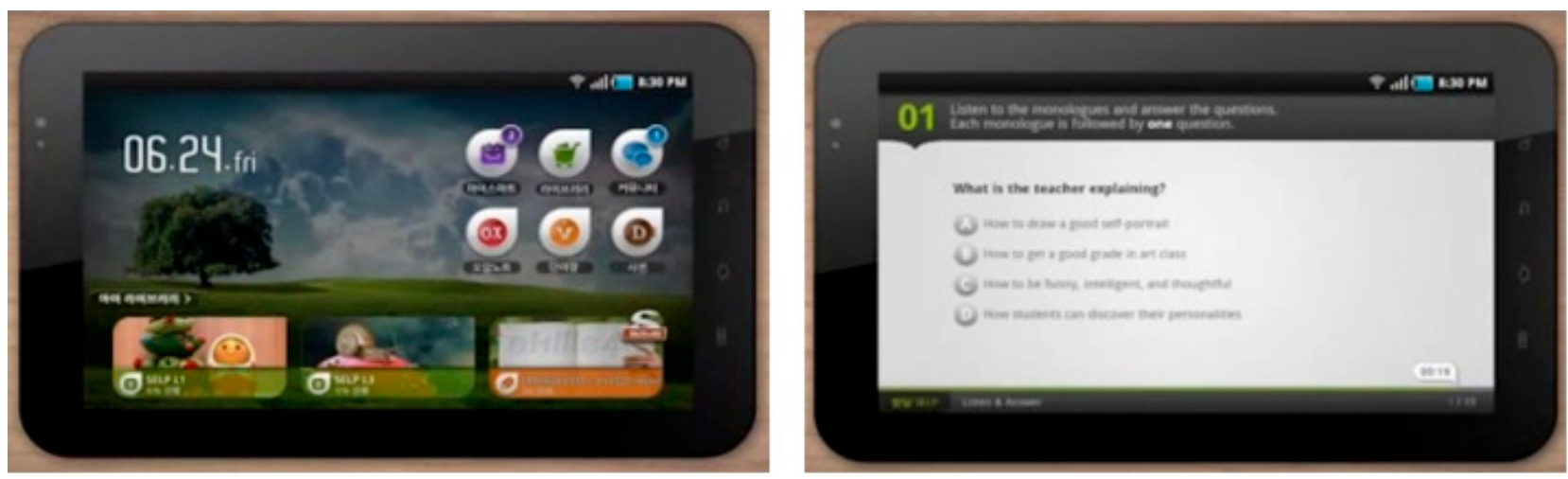

Figure 8. Actual appearance of T Smart Learning.

\subsection{Discussions and Implications}

The proposed framework was validated by applying it to a practical case in the illustration part. Although many cases can be utilized for complete validation, this paper performed an in-depth analysis in the T Smart Learning case to investigate the details of the framework. Consequently, the systematic approach to develop a service-oriented PSS enabled us to successfully generate creative ideas, design a service, and develop a PSS by reflecting the interaction between service providers and 
product partners. The most important part in the validation is how much users are satisfied with the practicality of the suggested approach. The TFT members in the aforementioned case highlighted the usefulness of four stages and techniques in each stage such as QFD and scenario analysis. In addition, active feedbacks among stakeholders could facilitate the process of developing the PSS.

However, several critical points should be considered to elevate the quality of application of the proposed approach. In the idea generation and selection stage of our case study, the TFT members of service providers had difficulty defining functions and judging their development potential. They also had difficulty separating them into hardware and software products because of the lack of knowledge and product development experience. At this time, the TFT members of the product partners played a key role in checking the feasibility of the functions and classifying them. On the contrary, the members of product partners who had a rudimentary understanding of the service gained a deeper understanding through the steps of deriving functions and conducting the AHP method, and this positively influenced the development of the requisite product in service-oriented PSS. Thus, it is definitely necessary to involve the product partners in the idea generation and selection stage.

The service providers and product partners should communicate and interact during the service design and product development stages. Through efficient and effective communication feedback is exchanged and incorporated into service design and product development. If miscommunication occurs at this point, the project team will not achieve satisfactory results. In our case, all TFT members got together and shared the progress of service design and product development once every two weeks. In spite of that, the project schedule was actually delayed due to miscommunication. Thus, it is necessary to execute more research on a systematic method for effective communication between the service design and product development teams. In this regard, Kleinsmann et al. [44] found factors that influence the creation of a shared understanding in collaborative new product development, and they also identified four collaboration types and their mechanisms. A similar study of PSS development would provide valuable findings and implications.

It is not easy to develop a new hardware product for service-oriented PSS. In our case, a general-purpose tablet PC was employed, contrary to the initial objective, although the hardware product partner still aimed to develop a new device that specialized in English education. Since the development of a new hardware product is highly risky in terms of cost and time, the service provider should consider customizing a general-purpose hardware product from its inception. Thus, the decision-making step on whether to develop or customize should be included in future research on the service-oriented PSS development process.

\section{Conclusions}

This paper proposes a service-oriented PSS development process in which the PSS development project is initiated and led by a service provider from a service-centric point of view. The proposed process, which is based on the product development process, service development process, and cases of PSS development projects, consists of four stages: (1) strategic planning; (2) idea generation and selection; (3) service design; and (4) product development. For each stage, actors and detailed procedures, including key features and useful methods, are suggested. Additionally, the real PSS 
development case of an English education service is introduced in detail as a demonstration of the application of the proposed process.

The contribution of this paper is that it expands the current scope of PSS research by suggesting the concept and development process of service-oriented PSS from the service provider's viewpoint, contrary to the manufacturer's viewpoint of existing studies. This can establish a foundation for research on service-oriented PSS development. Moreover, the proposed process and illustration are expected to serve as a useful guideline when service providers develop a service-oriented PSS.

However, this paper has some limitations. Firstly, the majority of the proposed process covers qualitative aspects. If more quantitative methods are added to the process, the proposed process can be made more systematic. Thus, the systematic and quantitative approach to partner selection, idea generation, service design, and collaboration with product partners are future research topics. Secondly, the case presented in this paper covers only specific industry sectors. Numerous case studies of broad industry sectors can provide us with worthwhile implications for service-oriented PSS development. In particular, cases of proven market success could confirm the validity of the proposed process. Therefore, in-depth case studies of various industries including successful cases could be another line of future research. Thirdly, since this research focuses on the PSS development process, subsequent processes such as a launching and operating process were not dealt with in this paper. Unique characteristics of PSS can be reflected to implement the details of the launching and operating processes. Thus, future research can present a complete framework of service-oriented PSS development from planning to operation by including the launching and operating process.

\section{Acknowledgments}

This work was supported by the National Research Foundation of Korea Grant funded by the Korean Government (NRF-2014R1A1A2054892).

\section{Author Contributions}

Seungkyum Kim designed the study, outlined the methodology, analyzed the data, interpreted the results and wrote the manuscript. Changho Son analyzed the data and wrote the manuscript. Byungun Yoon designed the study and wrote the manuscript. Yongtae Park implemented the research, designed the study, outlined the methodology, and helped complete the draft of this research. All authors have read and approved the final manuscript.

\section{Conflicts of Interest}

The authors declare no conflict of interest. 


\section{Appendix}

Table A1. 34 Function sets and AHP results.

\begin{tabular}{|c|c|c|c|c|c|c|}
\hline \multirow{2}{*}{$\begin{array}{l}\text { User } \\
\text { Group }\end{array}$} & \multirow[b]{2}{*}{ Function Sets } & \multicolumn{4}{|c|}{ AHP Results } & \multirow[b]{2}{*}{ Note } \\
\hline & & $\begin{array}{c}\text { Effectiveness } \\
\text { of Learning }\end{array}$ & $\begin{array}{c}\text { Personalized } \\
\text { Learning }\end{array}$ & Competitiveness & $\begin{array}{l}\text { Overall } \\
\text { Priority }\end{array}$ & \\
\hline student & writing-specialized & 0.05249 & 0.05220 & 0.08347 & 0.06317 & core function \\
\hline student & speaking-specialized & 0.05517 & 0.05220 & 0.05839 & 0.05596 & core function \\
\hline student & listening-specialized & 0.05438 & 0.05220 & 0.05839 & 0.05553 & core function \\
\hline student & reading-specialized & 0.05431 & 0.05220 & 0.05839 & 0.05549 & core function \\
\hline student & personal care & 0.05309 & 0.05220 & 0.05839 & 0.05482 & core function \\
\hline teacher & interaction in class & 0.03939 & 0.05986 & 0.06446 & 0.05032 & $\begin{array}{c}\text { core function } \\
\text { (teacher-support) }\end{array}$ \\
\hline teacher & auto-correction & 0.05693 & 0.04637 & 0.03691 & 0.04884 & $\begin{array}{c}\text { core function } \\
\text { (teacher-support) }\end{array}$ \\
\hline student & dictionary & 0.05161 & 0.04637 & 0.03691 & 0.04595 & \\
\hline teacher & auto-grading & 0.04297 & 0.04402 & 0.03739 & 0.04116 & $\begin{array}{c}\text { core function } \\
\text { (teacher-support) }\end{array}$ \\
\hline student & note & 0.04175 & 0.02700 & 0.03615 & 0.03819 & \\
\hline student & planner & 0.04283 & 0.01653 & 0.02806 & 0.03482 & \\
\hline student & diagnosis & 0.02942 & 0.03376 & 0.03715 & 0.03258 & \\
\hline student & push contents & 0.03615 & 0.01263 & 0.01679 & 0.02686 & \\
\hline student & contents library & 0.02209 & 0.02926 & 0.03220 & 0.02638 & \\
\hline student & game & 0.02837 & 0.03330 & 0.02007 & 0.02604 & \\
\hline teacher & checking homework & 0.02182 & 0.03009 & 0.03117 & 0.02597 & $\begin{array}{c}\text { core function } \\
\text { (teacher-support) }\end{array}$ \\
\hline teacher & making tests & 0.02755 & 0.01008 & 0.01998 & 0.02300 & $\begin{array}{c}\text { core function } \\
\text { (teacher-support) }\end{array}$ \\
\hline teacher & making teaching material & 0.01824 & 0.03138 & 0.02745 & 0.02288 & $\begin{array}{c}\text { core function } \\
\text { (teacher-support) }\end{array}$ \\
\hline student & communication & 0.02073 & 0.01957 & 0.02633 & 0.02254 & \\
\hline student & search & 0.03144 & 0.01354 & 0.01139 & 0.02253 & \\
\hline parent & informing of diagnosis results & 0.02337 & 0.01279 & 0.01139 & 0.01806 & $\begin{array}{c}\text { core function } \\
\text { (parent-support) }\end{array}$ \\
\hline parent & informing of progress & 0.01537 & 0.02573 & 0.01967 & 0.01800 & $\begin{array}{c}\text { core function } \\
\text { (parent-support) }\end{array}$ \\
\hline student & counseling & 0.01593 & 0.01276 & 0.02117 & 0.01739 & \\
\hline teacher & class/student management & 0.01538 & 0.01974 & 0.01211 & 0.01473 & $\begin{array}{c}\text { core function } \\
\text { (teacher-support) }\end{array}$ \\
\hline teacher & communication with parents & 0.01499 & 0.01974 & 0.01211 & 0.01452 & \\
\hline parent & informing of attitude in class & 0.01394 & 0.02704 & 0.01072 & 0.01427 & $\begin{array}{l}\text { core function } \\
\text { (parent-support) }\end{array}$ \\
\hline parent & intimacy & 0.01190 & 0.02276 & 0.01160 & 0.01300 & $\begin{array}{c}\text { core function } \\
\text { (parent-support) }\end{array}$ \\
\hline parent & education-related information & 0.01226 & 0.01660 & 0.01215 & 0.01270 & $\begin{array}{l}\text { core function } \\
\text { (parent-support) }\end{array}$ \\
\hline
\end{tabular}


Table A1. Cont.

\begin{tabular}{|c|c|c|c|c|c|c|}
\hline \multirow{2}{*}{$\begin{array}{c}\text { User } \\
\text { Group }\end{array}$} & \multirow[b]{2}{*}{ Function Sets } & \multicolumn{4}{|c|}{ AHP Results } & \multirow[b]{2}{*}{ Note } \\
\hline & & $\begin{array}{c}\text { Effectiveness } \\
\text { of Learning }\end{array}$ & $\begin{array}{c}\text { Personalized } \\
\text { Learning }\end{array}$ & Competitiveness & $\begin{array}{l}\text { Overall } \\
\text { Priority }\end{array}$ & \\
\hline student & synchronization & 0.01073 & 0.01974 & 0.01211 & 0.01220 & \\
\hline teacher & other teacher-support & 0.00889 & 0.02055 & 0.01160 & 0.01112 & \\
\hline student & help & 0.01079 & 0.01092 & 0.01008 & 0.01056 & \\
\hline teacher & student control & 0.00920 & 0.00852 & 0.01095 & 0.00973 & \\
\hline student & timer & 0.00789 & 0.01206 & 0.01160 & 0.00964 & \\
\hline parent & nurture-related information & 0.00696 & 0.01014 & 0.01139 & 0.00885 & $\begin{array}{c}\text { core function } \\
\text { (parent-support) }\end{array}$ \\
\hline
\end{tabular}

\section{References}

1. Martinez, V.; Bastl, M.; Kingston, J.; Evans, S. Challenges in transforming manufacturing organizations into product-service providers. J. Manuf. Technol. Manag. 2010, 21, 449-469.

2. Goedkoop, M.J.; van Halen, C.J.G.; te Riele, H.R.M.; Rommens, P.J.M. Product Service Systems, Ecological and Economic Basis; Technical Report; Pre Consultants: Amersfoort, The Netherlands, 1999.

3. Baines, T.S.; Lightfoot, H.W.; Evans, S.; Neely, A.; Greenough, R.; Peppard, J.; Roy, R.; Shehab, E.; Braganza, A.; Tiwari, A.; et al. State-of-the-art in product-service systems. Proc. Inst. Mech. Eng. Part B 2007, 221, 1543-1552.

4. Low, M.K.; Lamvik, T.; Walsh, K.; Myklebust, O. Manufacturing a green service: Engaging the TRIZ model of innovation. IEEE Trans. Electron. Packag. Manuf. 2001, 24, 10-17.

5. Alonso-Rasgado, T.; Thompson, G. A rapid design process for Total Care Product creation. J. Eng. Des. 2006, 17, 509-531.

6. Aurich, J.C.; Fuchs, C.; Wagenknecht, C. Life cycle oriented design of technical Product-Service Systems. J. Clean. Prod. 2006, 14, 1480-1494.

7. Tan, A.R.; McAloone, T.C.; Gall, C. Product/service-system development-An explorative case study in a manufacturing company. In Proceedings of the International Conference on Engineering Design 2007, Paris, France, 28-31 August 2007.

8. Uchihira, N.; Kyoya, Y.; Kim, S.; Maeda, K.; Ozawa, M.; Ishii, K. Analysis and Design Methodology for Recognizing Opportunities and Difficulties for Product-based Services. In Proceedings of the PICMET 2007, Portland, OR, USA, 5-9 August 2007.

9. Sakao, T.; Sandström, G.Ö.; Matzen, D. Framing research for service orientation of manufacturers through PSS approaches. J. Manuf. Technol. Manag. 2009, 20, 754-778.

10. Shimomura, Y.; Hara, T.; Arai, T. A unified representation scheme for effective PSS development. CIRP Ann.-Manuf. Technol. 2009, 58, 379-382.

11. Yang, X.; Moore, P.; Pu, J.; Wong, C. A practical methodology for realizing product service systems for consumer products. Comput. Ind. Eng. 2009, 56, 224-235.

12. Wong, M. Implementation of innovative product service-systems in the consumer goods industry. Ph.D. Thesis, University of Cambridge, Department of Engineering, Cambridge, UK, 2004.

13. Mont, O. Clarifying the concept of product-service system. J. Clean. Prod. 2002, 10, 237-245. 
14. Manzini, E.; Vezzoli, C. A strategic design approach to develop sustainable product service systems: Examples taken from the "environmentally friendly innovation" Italian prize. J. Clean. Prod. 2003, 11, 851-857.

15. Tukker, A. Eight types of product service system: Eight ways to sustainability experiences from SusProNet. Bus. Strateg. Environ. 2004, 13, 246-260.

16. Krucken, L.; Meroni, A. Building stakeholder networks to develop and deliver product-service-systems: Practical experiences on elaborating pro-active materials for communication. J. Clean. Prod. 2006, 14, 1502-1508.

17. Tukker, A.; Tischner, U. New Business for Old Europe: Product-Service Development, Competitiveness and Sustainability; Greenleaf Publishing: Sheffield, UK, 2006.

18. Tukker, A.; van Halen, C. Innovation Scan for Product Service Systems: Manual; TNO: Delft, The Netherlands; PricewaterhouseCoopers: Utrecht, The Netherlands, 2003.

19. Suh, J.; Park, S. Service-oriented Technology Roadmap (SoTRM) using patent map for R\&D strategy of service industry. Expert Syst. Appl. 2009, 36, 6754-6772.

20. Lee, S.; Kim, Y. A product-service system design method integrating service function and service activity and case studies. In Proceedings of the 2nd CIRP IPS2 Conference, Linköping, Sweden, 14-15 April 2010.

21. Chen, J.; Huang, C. A TRIZ based eco-innovation method for PSS. In Proceedings of the 16th CIRP International Conference on Life Cycle Engineering, LCE 2009, Cairo, Egypt, 4-6 May 2009.

22. Chen, J.; Li, H. Innovative design method of product service system by using case study and TRIZ model. In Proceedings of the 2nd CIRP IPS2 Conference, Linköping, Sweden, 14-15 April 2010.

23. Genrich, A.; Shulyak, L. And Suddenly the Inventor Appeared: TRIZ, the Theory of Inventive Problem Solving; Technical Innovation Center, Inc.: Worcester, UK, 1996.

24. Domb, E. QFD and TIPS/TRIZ. Available online: http://www.trizjournal.com/archives/1998/06/c/ index.htm (accessed on 23 October 2015)

25. Yamashina, H.; Ito, T.; Kawada, H. Innovative product development process by integrating QFD and TRIZ. Int. J. Prod. Res. 2002, 40, 1031-1050.

26. Uhlmann, E.; Stelzer, C. Identifiaction of the IPS2 business model in the early stage of creation. In Proceedings of the 2nd CIRP IPS2 Conference, Linköping, Sweden, 14-15 April 2010.

27. Meier, H.; Kroll, M. From products to solutions-IPS2 as a means for creating customer value. In Proceedings of the 16th CIRP International Conference on Life Cycle Engineering, LCE 2009, Cairo, Egypt, 4-6 May 2009.

28. Manzini, E.; Collina, L.; Evans, S. Solution Oriented Partnership: How to Design Industrialised Sustainable Solutions; Cranfield University: Cranfield, UK, 2004.

29. Morelli, N. Developing new product service systems (PSS): Methodologies and operational tools. J. Clean. Prod. 2006, 14, 145-1501.

30. Schuh, G.; Gudergan, G. Service engineering as an approach to designing industrial product service systems. In Proceedings of the 1st CIRP Industrial Product-Service Systems (IPS2) Conference, Cranfield, UK, 1-2 April 2009.

31. Hauser, J.R.; Clausing, D. The house of quality. Harvard Business Review, May 1988, pp. 63-73.

32. Umeda, Y.; Tsutsumida, M.; Tomiyama, T.; Tamura, T.; Fujimoto, J. Study on feasibility of service-oriented products using life cycle simulation. J. Jpn. Soc. Des. Eng. 2001, 36, 517-526. 
33. Fujimoto, J.; Umeda, Y.; Tamura, T.; Tomiyama, T.; Kimura, F. Development of service-oriented products based on the inverse manufacturing concept. Environ. Sci. Technol. 2003, 37, 5398-5406.

34. Cooper, R.G.; Edgett, S.J.; Kleinschmidt, E.J. Optimizing the stage-gate process: What best-practice companies do-I. Res. Technol. Manag. 2002, 45, 21-27.

35. Cooper, R.G.; Edgett, S.J.; Kleinschmidt, E.J. Optimizing the stage-gate process: What best-practice companies do-II. Res. Technol. Manag. 2002, 45, 43-49.

36. Brügemann, L.M. Innovation of an Eco-efficient Product-Service Combination. Master's thesis, Delft University of Technology, Delft, The Netherlands, 2000.

37. Chesbrough, H. Open innovation: Where we've been and where we're going. Res. Technol. Manag. 2012, 55, 20-27.

38. Emden, Z.; Calantone, R.J.; Droge, C. Collaborating for new product development: Selecting the partner with maximum potential to create value. J. Prod. Innov. Manag. 2006, 23, 330-341.

39. Saaty, T.L. The Analytic (Hierarchy) Process; McGraw-Hill: New York, NY, USA, 1980.

40. Saaty, T.L. Decision making for leaders. IEEE Trans. Syst. Man Cybern. 1985, 15, 450-452.

41. Saaty, T.L. How to make a decision: The analytic hierarchy process. Eur. J. Oper. Res. 1990, 48, 9-26.

42. Vaidya, O.S.; Kumar, S. Analytic hierarchy process: An overview of applications. Eur. J. Oper. Res. 2006, 169, 1-29.

43. Soni, A.; Cohen, H. Successfully launching your product: Getting it right. Handb. Bus. Strateg. 2004, 5, 263-268.

44. Kleinsmann, M.; Buijs, J.; Valkenburg, R. Understanding the complexity of knowledge integration in collaborative new product development teams: A case study. J. Eng. Technol. Manag. 2010, 27, 20-32.

(C) 2015 by the authors; licensee MDPI, Basel, Switzerland. This article is an open access article distributed under the terms and conditions of the Creative Commons Attribution license (http://creativecommons.org/licenses/by/4.0/). 